This item was submitted to Loughborough's Research Repository by the author.

Items in Figshare are protected by copyright, with all rights reserved, unless otherwise indicated.

\title{
Defining a framework for the evaluation of information
}

PLEASE CITE THE PUBLISHED VERSION

PUBLISHER

(C) Inderscience

VERSION

AM (Accepted Manuscript)

LICENCE

CC BY-NC-ND 4.0

REPOSITORY RECORD

Darlington, M.J., S.J. Culley, Yuyang Zhao, Simon A. Austin, and L.C.M. Tang. 2019. "Defining a Framework for the Evaluation of Information". figshare. https://hdl.handle.net/2134/4226. 
This item was submitted to Loughborough's Institutional Repository (https://dspace.lboro.ac.uk/) by the author and is made available under the following Creative Commons Licence conditions.

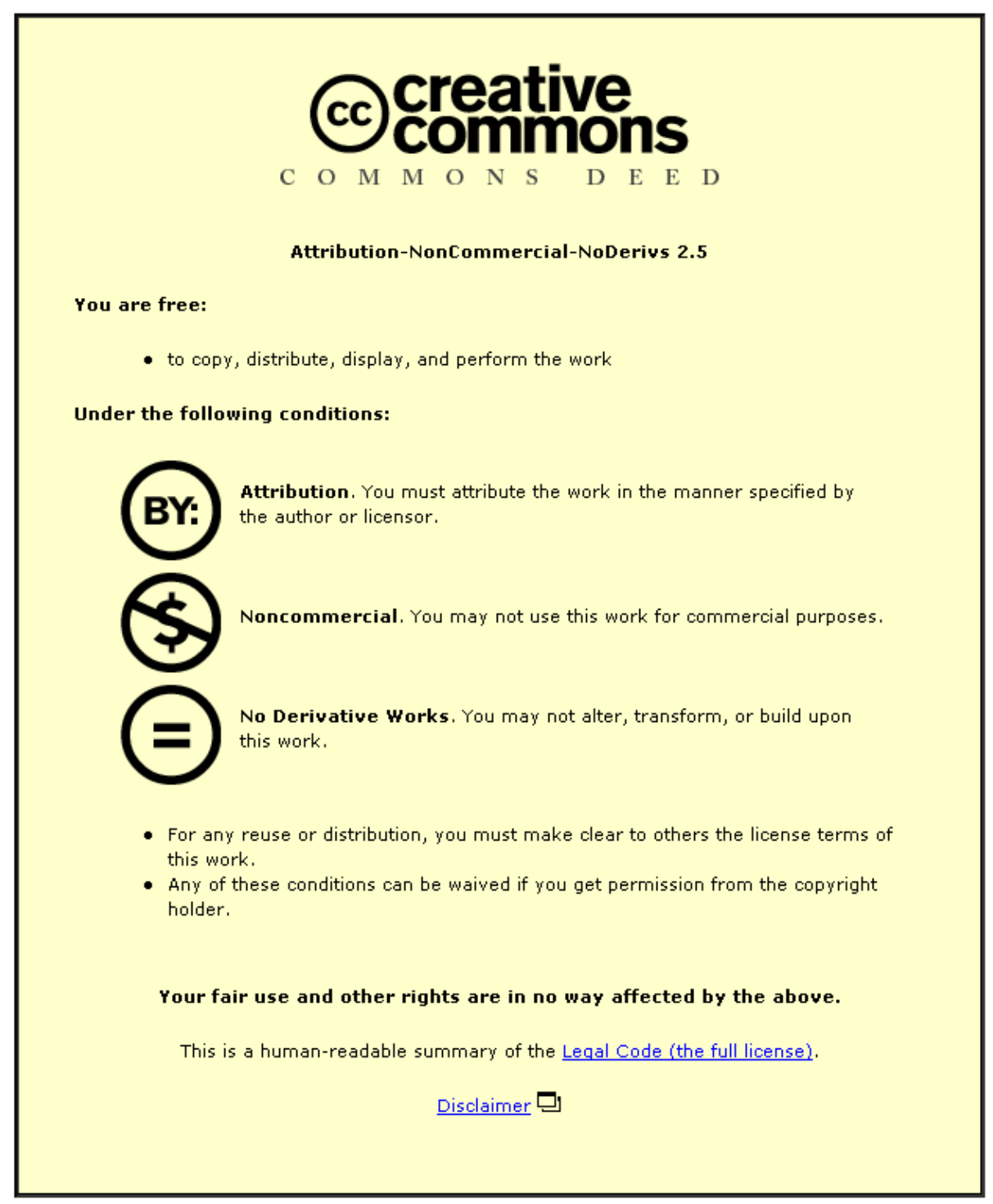

For the full text of this licence, please go to: http://creativecommons.org/licenses/by-nc-nd/2.5/ 


\title{
DEFINING A FRAMEWORK FOR THE EVALUATION OF INFORMATION
}

\author{
Darlington, M., Culley, S.J., Zhao, Y., Austin, S.A. \& TANG, L. ${ }^{2}$
}

IdMRC, Department of Mechanical Engineering, University of Bath, Claverton Down, Bath, BA2 7AY, England ${ }^{1}$

Email: ensmjd@bath.ac.uk; ensscj@bath.ac.uk; y.zhao@bath.ac.uk

IMCRC, Department of Civil and Building Engineering, Loughborough University, Loughborough, Leics, LE11, England ${ }^{2}$

Email: S.A.Austin@lboro.ac.uk; C.M.Tang@lboro.ac.uk

* Corresponding author

\begin{abstract}
In any enterprise, principled decisions need be made during the entire life cycle of information about its acquisition, storage, creation, maintenance and disposal. Such information management requires some form of information evaluation to take place, yet little is understood about the process of information evaluation within enterprises. For evaluation support to be both effective and resource efficient, particularly where decisions are being made about the future of large quantities of information, it would be invaluable if some sort of automatic or semi-automatic methods were available for evaluation. Such a method would require an understanding of the diversity of the contexts in which evaluation takes place so that evaluation support can have the necessary context-sensitivity. This paper identifies the dimensions that influence the information evaluation process and defines the elements that characterize these dimensions, thus providing the foundations for a context-sensitive framework for information evaluation.
\end{abstract}

Keywords: information value and evaluation; through-life information support, information life cycle, information preservation, information curation

Biographical notes: Mansur Darlington is a Research Officer in the Design Information \& Knowledge Group of the IdMRC at the University of Bath. He joined the University from industry in 1997, and has a degree in Cognitive Science from the University of Exeter and a Ph.D. in Engineering Cognition from the University of Bath. For the last ten years he has been involved in research associated with the capture and codification of engineers' design knowledge and the development of methods for supporting engineers' information needs, first in the University of Bath's Engineering 
Design Centre, latterly in the Innovative Design \& Manufacturing Research Centre. He is currently Project Manager for the KIM Grand Challenge research project and research task co-ordinator for KIM Work Package 2 'Learning from Use'.

Steve Culley is Professor in Engineering Design and Head of Design in the Department of Mechanical Engineering at the University of Bath. He has researched in the engineering design field for many years. In particular, this has included the provision of information and support to engineering designers. Steve pioneered work in the introduction and use of the electronic catalogue for standard engineering components and has extended this work to deal with systems and assemblies. His chief interests are in documentation to support engineering design and methodologies to support design for changeover.

Yuyang Zhao is a Research Officer within the IdMRC at the University of Bath. His education background includes B.Eng. and M.Sc. in chemical machinery and equipment, and a Ph.D. in chemical engineering in China. He has research experience in the data model development for STEP (ISO10303) and ISO15926 for process industry during his Ph.D. studentship. He started his research career in 2001 in the University of Manchester and focused on the engineering information retrieval, information flow analysis and modeling, knowledge representation, document control, and especially the validation process for industry. He is now working on developing measures of information value and approaches to the support of decision-making on information retention.

Simon Austin is Professor of Structural Engineering in the Department of Civil and Building Engineering at Loughborough University. He is also the founder director of Adept Management, a specialist management consultancy. Prior to this he worked for Scott Wilson Kirkpatrick \& Partners and Tarmac Construction. He has undertaken industry-focused research for over 25 years into design processes, modeling, integrated working and management techniques, information management, process re-engineering, value management and structural materials and their design. The later includes the building design process, behaviour and design of structural elements and innovative sprayed and cast concretes and mortars.

Llewellyn C.M. Tang is a Research Associate in the Department of Civil and Engineering at Loughborough University working for the KIM project 'Immortal Information and Through-life Knowledge Management' with special interest in information evaluation in the construction and aerospace industry sectors. He has researched and lectured in the field of decision science since he obtained a first-class honors degree in Construction Engineering and Management and a Ph.D. in Knowledge and Innovation Management in Hong Kong. As a scholar, he has obtained several scholarships and fellowships from a number of prestigious institutions. His research interests are artificial intelligence, cash flow forecasting, computational decision support, operational research, information processing and knowledge management. 


\section{INTRODUCTION}

The research reported in this paper is part of the EPSRC (Earth \& Physical Sciences Research Council) Grand Challenge research project entitled 'Immortal Information and Through-life Knowledge Management: Strategies and Tools for the Emerging ProductService Business Paradigm' (KIM, 2007). The project focuses on understanding and developing support for the information and knowledge needs of engineering and construction companies engaged in delivering product-service through the life of the product. Engineering activities - from product design to end-of-life disposal - generate very large amounts of information and knowledge, and the life-cycles of the physical artefacts and the information (Tallon \& Scannell, 2007; Treasury Board of Canada, 2004; Borgman, 1996) parallel one another. The availability of too much or too little information can be damaging to the performance of individuals and organisations. As suggested below, strategies are needed which support the evaluation of information so that principled decisions can be made during its entire life cycle about acquisition, storage, creation, maintenance and disposal.

The research reported here has been carried out in the engineering domain (principally in the mechanical, aerospace and construction sectors). Nevertheless, the purpose of this paper is to enter in to a discussion about an under-researched area of general interest. The authors believe that the understanding gained can be usefully generalizable to other enterprise domains since the business processes underpinning the engineering activity are common to many operations irrespective of scale or domain.

The approach to information management taken by many organisations - in the absence of suitable information minimization strategies - has been to gather all information regardless of cost and relevance; yet at the same time (see Inc. Staff, 2003) it is known that as much as 80 per cent of information that is retained is never used. To some extent the 'keep-all' approach is driven by legislative requirements (perceived as much as real) and contingency planning in the face of uncertainty, but it is driven too by uncertainty about how to assess and assign value. Much information is not useful yet is kept, much could prove very valuable but may be difficult to find or understand later in the product life cycle because it has not been subjected to evaluation and strategies for maximizing potential future use.

This retention approach leads to, amongst other things, 'information overload' manifested in different ways. Problems of information overload have been recognized and discussed for at least 30 years (Eppler \& Mengis, 2004; Edmunds \& Morris, 2000) and these problems worsen progressively as new technological developments for the production of information continue to outpace the capacity to deal with it. Waddington (1996) recorded that the existence of too much information was a serious challenge to business, even then leading to substantial amounts of time being absorbed in collecting and looking for information, and the deleterious effect of 'analysis paralysis' brought on by the existence of more information than can be efficiently dealt with.

New methods are needed which allow good decisions to be made about what information to keep (preservation) how it might be enhanced and given added value (curation) and what information to invest in for the future (provision) (Macdonald \& Lord, 2002). Furthermore, support is required to allow good decisions to be made about information in terms of its capacity to satisfy the current problem-solving or decisionmaking need. To do this effectively a better understanding must be gained of what 
constitutes value in information, and new methods and metrics developed for supporting the evaluation process. Without these things the necessary continuity, usefulness and accessibility of information will not be achieved - especially over long information life cycles. As a basis for good decision-making in respect of information management, chief amongst the questions to be asked is 'how valuable is this information?' There is little support at present to answer this question. Clearly, then there is a motivation for understanding how this question might be answered in the context of an enterprise activity. In this context, for evaluation to be both effective and resource efficient it is necessary that the investment in resources associated with information evaluation specifically that of human intervention - be minimized. (This is particularly the case where large information repositories or large numbers of information entities are being evaluated.) To do this the basis must be found for automatic or semi-automatic evaluation methodologies and tools.

Associated reports concerning the authors' work in reviewing existing approaches to information evaluation, identifying information attributes and metrics, and the development of a number of approaches to automatic information evaluation can be found elsewhere (e.g. Tang et al., 2007; Zhao et al., 2007, Zhao et al., 2008a, Zhao et al., 2008b). Much of the underlying theoretical and empirical work which supports the work reported here can be found in these papers. In particular, the readers' attention is drawn to a companion work to this (Darlington et al., 2008), which discusses and defines concepts associated with the characterization of information for the purposes of evaluation. These concepts include the principal characteristics identified by the authors as being central to information evaluation including accuracy, usability, trustworthiness (which together constitute quality), currency, benefit, impact, cost and relevance.

This paper discusses the foundations of a framework for information evaluation, in particular the clarification and definition of the concepts which constitute the buildingblocks and structure of such a framework. These concepts include the objects of the evaluation (Section 2) the evaluation process itself and the contexts in which it occurs (Section 3.1) and the motivations for evaluation (Section 3.2). Consideration is given also to the influence of the information life cycle on evaluation (Section 3.3). The variables introduced dictate the overall circumstances in which any evaluation takes place. For each circumstance, specific characteristics of information will be important to the evaluation process requiring, perhaps, different methods and metrics for value assessment. Furthermore different motivations will be found in combination with these contexts at different parts of the information life-cycle which drive and colour the information evaluation process. These naturally occurring variations suggest that any attempt at universally applicable approach to information evaluation will not be effective. Rather, the supported process of information evaluation, informed by method and mechanism, must be sensitive to the considerable variation found. This is especially the case if the evaluation is to be automatic or semi-automatic in order to reduce resource overheads.

It should be recognized here that the topic of information value and evaluation has received little attention, in contrast with, say, information search and relevance ranking. The work that has been done has been characteristically domain specific and is not unified (see Zhao, 2007). The authors' evaluation framework is thus presented here tentatively in the light of the fact that this area of research is still in its infancy. 
It is necessary in this paper to introduce a number of concepts and their definitions. The concepts have been identified and developed over the course of previous research work, case studies with industry collaborators and research currently in progress. Meadows \& Yaun (1997) support the view expressed by Felix Cohen (Cohen, 1950) that what is required of a definition is not that it is true or false but is useful in communication. They quote Felix Cohen’s pragmatic approach:

Once we recognize that a definition is, strictly speaking, neither true nor false but rather a resolution to use language in a certain way, we are able to pass the only judgment that ever needs to be passed on a definition, a judgment of utility or inutility.

It is in this spirit of pragmatism and utility that the definitions are proposed here.

\section{The OBJects of Evaluation}

Definitions of information abound and in spite of some attempts toward standardization (e.g. Meadows \& Yuan, 1997, on behalf of information professionals) there is still a great diversity in usage and interpretation. Reflecting specifically on information evaluation, the authors have adopted and developed a number of definitions which facilitate exploration of this subject and the process of evaluation as a practical activity within the context of the practice of engineering, and more generally within the activities of an enterprise.

Information has value because it 'informs' understanding and knowledge and leads to directed behaviour or action (Machlup \& Mansfield, 1980). Likewise, in Buckland's (1991) triplet of information types one manifestation of information is 'information as knowledge'. These interpretations provide the basis for the author's description of information:

Information is the meaningful content of a description or message which, when interpreted, allows a change in knowledge state.

It is clear however, that information thus described is 'abstract and intangible, immaterial' (Curtis Wright, 1976) and thus, whilst it can be said to have value, information per se is, practicably speaking, a difficult object of evaluation. Buckland however, also considers information as thing, where

'the term 'information' is used attributively for objects such as data and document, because they are regarded as being informative, as "having the quality of imparting knowledge or communicating information; instructive." (Oxford English Dictionary, 1989, vol. 7, p. 946).'

This useful identification of information as tangible objects (see Figure 1) provides the foundation for considering practical objects for evaluation.

In the next section the information object is discussed in detail and defined, as are two further associated information entities which are foundational to information evaluation.

]Figure 1 near here] 


\subsection{The Information Object}

The authors have adopted the term 'information object' for the principal class of tangible information entity, to which the other two manifestations associate in a loose part-whole relation.

The term information object is rather compelling and has been used variously (e.g. CCSDS, 2002; Currall \& McKinney, 2006; Ziade \& Kittredge, 2005). In particular, it has been defined by Ziade and Kittredge as:

'... an item of information that has an object-like form or takes on object-like characteristics.'

Ziade and Kittredge (2005) have in mind the 'information object' as being a cognitive object which is suggestive of a real object (even where none exists) and which can help humans make more tangible something that often (as a digital entity) has no direct physical analogue in the real world. This object, they say, conveys objectiveness by being 'delineated'; that is, providing some 'visual hints that some information is discrete and stands on its own relative to other information'. They also cite 'headlining' (i.e. giving an explicit title to) and spacing (i.e. making information appear spatially separate) and 'wrapping' as being good ways to 'objectivize' information. All these apply equally to physical objects, of course.

It is exactly information entities which are objectivized (i.e. made objects) in the way that they suggest which are the natural objects of evaluation, rather than information as an intangible. The archetype of the information object - particularly within the engineering domain - might be considered the document, defined by Glushko and McGrath (2005) as 'a purposeful and self-contained collection of information'.

Although their definition 'focuses on the information content, not on the physical container or medium, format, or technology ...' it contains the important words 'purposeful' and 'self-contained' (thereby suggesting some 'container') the latter recapitulating Ziade \& Kittredge's idea of 'delineated'. These characteristics, it seems, are essential to all information objects if they are to be susceptible to evaluation. Commonly in the engineering domain such an entity consists of text and images presented in a linear and structured manner as exemplified by a technical report or operations manual. For the sake of inclusivity, however, the concept of information object must be extended to embrace different manifestations of information objects. It is possible to embrace all manifestations of the information object by two main classes of object type, viz:

- Physical objects that is things that can be 'held in the hand' (e.g. a printed document, a book, etc.).

- Electronic objects, including:

o Those which are analogues of physical objects.

o Those with no physical analogue (e.g. many web pages, interactive models).

o Those which are dynamic (e.g. a real-time simulation or 3-D rotating models). 
Some instances of these, in their way, convey or carry information in a 'purposeful and self-contained way' and have contextualizing associated information, and therefore qualify themselves as information objects.

Ziade and Kittredge's purposefulness and self-containment, however, are insufficient to fully characterise the information object. Additional to this is the requirement for ready identification, that is to say, meta-information that places the information contained into some recognizable individuating context. Consider a familiar information object such as a book; it has a natural physical container, which makes it of a recognizable sort, and identification reinforced by a conventional internal structure. Conventionally it bears a (often unique) title, and contains information about the author, its publisher, unique identification number and so on. This is clearly an information object as defined. Strip away the form and the structure and the conventions of contextual information and certainly there is information, but for the purposes of evaluation, no recognizable and uniquely identifiable instance of an object.

Less explicitly so, but nonetheless an information object, there is, for example, the readable and interpretable content of an engineer's CAD model. The medium for representation is quite different; it is multi-faceted, perhaps almost infinitely reconfigurable, yet it has all the hallmarks of purposefulness, self-containment, and identifiable individuation of the physical book. It is a virtual information object. This notion can be extended further to embrace dynamic objects the information-bearing value of which are constituted only in real time. Since dynamic objects can be called into existence at will they are clearly evaluable.

Having clarified the conceptualization of the information object it is now possible to similarly treat information fragment and information system.

\subsection{The Information Fragment}

Information in a tangible form does not exist solely in the form of the information object as conceptualized here. Clearly, within information objects are items of information which themselves are separable from the information object itself, that nevertheless 'inform' and are of value but have none of the contextual identity of the information object. This suggests a lesser class of information carrier, which the authors refer to as the 'information fragment'. A fragment of information has no contextualizing information, nor conventional form. It might consist of as little as an item of numerical data or perhaps a visual element in a larger pictorial scheme, an informational subcomponents in a larger informational system; individually valuable (and evaluable) but not standing alone as individually identifiable object. Thus the authors' definition of Information Fragment is made in respect of the information object as:

An information fragment is any meaningful sub-part of an information object which is meaningful by virtue of the information it contains.

The relation between the information fragment and the information object can be visualized as shown in Figure 2.

[Figure 2 near here] 
It can be seen here than an information object (IO) may be constituted from a number of information fragments (IF) or objects together with the contextualizing metainformation. An example of the second case would be a printed volume existing in its own right, the contents of which are constituted from other information objects such as papers or collected articles, which may well retain their own individuating context information.

\subsection{The Information System}

Information can be seen as, indeed is sometimes defined as, both a resource and a commodity (Meadows \& Yuan, 1997); so too can the tangible manifestations of information. In particular, it seems clear that in consideration of evaluation, systems of information provision, which do not merely constitute information entities themselves but the paraphernalia for their organization and distribution, indeed their generation, are of interest both as resource and commodity. Examples of these are such things as the library, the operational database, the expert system, and so on. These things both convey information to (as resource) and represent evaluable assets of (as commodity) the individuals or enterprises which control or own them and are evaluable in both guises. The relation between the information system and the entities of which it is composed can be seen in Figure 3.

\section{[Figure 3 near here]}

It can be observed that data can be part of an information system. However, in the analysis presented here, a datum is not information-as-thing and therefore is not directly evaluable except in relation to an information system. It does, however, constitute a precursor to information-as-thing through the information system, which itself may generate an information object (for example a database report).

Thus the authors' definition of Information System is made in respect of the information object, information fragment and data as:

An information system is a physical or electronic system that combines a collection of data, information fragments or information objects with the infrastructure necessary to organize, collect, create, disseminate or deliver them

It should be emphasized that in each of the three cases of information-as-thing as conceptualized here that evaluation of the entity cannot be made without reference to the value of the information it contains. As such each information-as-thing stands as a proxy to the information it conveys.

\section{CONTEXT AND THE INFORMATION EVALUATION PROCESS}

In the previous section one important concept in information evaluation - the object of evaluation - has been illuminated. It is necessary now to consider a further highly influential concept - that of context.

Information evaluation does not occur in a vacuum, each instance of evaluation being characterized by the set of facts or circumstances that surround the event, that is to say the context. In an enterprise environment the context might be defined by such things as the task or activity being carried out, itself dictated by the circumstances of the 
evaluator, the role being fulfilled and so on.. Each context will be unique and made up of many interrelated elements inhabiting different contextual dimensions. These are common-sense observations.

The authors have identified a number of high-level contextual dimensions which are common to and influence the process of information evaluation within an enterprise environment.. Understanding these particularly influential and common dimensions provides the basis for the development of evaluation methods and metrics that might be appropriately applied to a given event. Each such events will be referred to henceforth as an Information Evaluation Event (IEE).

The authors hypothesize that the particulars of an IEE will be characterized chiefly by:

- The organizational dimension.

- The motivational dimension.

- The information life-cycle dimension.

These three dimensions and their relations are discussed in the following sections.

\subsection{The Organizational Dimension}

It can be readily observed that the activities carried out in an enterprise occur within different organizational levels. This notion is supported in the authors' work reported in Zhao, et al. (2008a) where distinct needs and practices can be distinguished between individuals who are fulfilling different rôles and operating at different levels in participant companies. Each one of these levels provides a perspective on information evaluation that results in differences of such things as aspects of information thought to be of principal importance, time-frame, object of evaluation, the sort of questions that are asked in evaluating and the types of decisions that result from evaluation. These differences reinforce the notion that there are (at least) three distinct perspectives from which evaluation may take place. These dimensions are interconnected and often reciprocally influential, that is to say one dimension, or elements thereof, defines or influences another dimension or elements. Although intersecting at their boundaries these three perspectives seem to have usefully distinguishing characteristic features. Distinguishing these perspectives may prove helpful in thinking about information evaluation and in developing methods and metrics for so doing.

\section{[Table 1 near here]}

The perspectives, shown in Table 1, are referred to by the authors as the personal perspective, the enterprise perspective and the corporate perspective. These terms are used just in a general sense to indicate at what operational level the activity of information evaluation might be involved. It should be understood, however, that no matter from what perspective an evaluation is made it is always the result of the judgement of one or more individuals acting in an appropriate level-associated rôle.

As can be seen, most closely related are the processes associated with the perspectives of enterprise and personal information evaluation. These deal with similar objects of evaluation (that is, information entity types) although at a different level of granularity (principally being interested in making evaluations in respect of information as a resource) and share many motivations/post-evaluative actions (see next section). 
Corporate-perspective evaluation, on the other hand, seems to be a process of a sort that is distinctly different in character from the other two. It considers information in terms of the systems that deliver it, sometimes as a resource, but chiefly as a commodity. Nevertheless, it should be observed that the boundaries between these three perspectives are not strictly fixed, as suggested in Table 1 by the hatched vertical lines.

The following sections consider the particulars of the process of evaluation at each of these organizational levels.

\subsubsection{The Personal Information Evaluation Process}

This process of information evaluation occurs when an individual makes an assessment of value of a piece of information in the context of a current need or a need that can be predicted in the near future. It is intimately associated with judging the current utility of information per se.

The sort of questions and framework that guide judgement making will be those identified in Column 2 of Table 1. Fundamentally, personal information evaluation is concerned with answering the question:

'Does this information help me to make a better decision for the task that I am doing or a task that I routinely or might predictably do as part of my work?'

Personal information is qualified as such by being involved in the personal information evaluation process. It is defined here as follows:

Personal information is any information that is needed by the individual as the basis for decision-making, problem-solving, understanding and planning during the normal course of work.

Personal information is almost boundless in terms of extent and form, ranging from, say, a data table to an operations manual, from a small sketch drawing to an entire 3D representation.

\subsubsection{Enterprise Information Evaluation Process}

The individual making information evaluation on the part of the enterprise may, for example, be responsible for populating the company intranet, be acting as company librarian, and so on. The sort of questions and framework that guide judgement making will be those identified in Column 3 of Table 1.

Fundamentally, enterprise information evaluation is concerned with answering the question:

'Is this information of sufficient use in its capacity to support a process or activity within the company to warrant being made available to a team or group or individual in anticipation of their likely tasks?'

The notion of 'warrant' embraces the idea of commitment of resources both financial and temporal. 
Enterprise information is qualified as such by being involved in the enterprise information evaluation process. It is defined here as follows:

Enterprise information is information which is made available by the company for the use of individuals or groups of individuals in order for them to carry out their day-today activities.

There is a strong element of prediction in this question since it is supposed that those involved in making enterprise-level information evaluation must make decisions about the likelihood of information being useful over the short to medium term.

Examples of enterprise information include such things as subscription information, the query-able content of databases, periodicals, standards, regulations, best practice guides, internal reports (as representative of the myriad output from other internal activities) and so on.

\subsubsection{The Corporate Information Evaluation Process}

Characteristically, information evaluation at the corporate level is predominantly concerned with the instruments of information delivery. When it is so, it may be concerned with the value of that system as a whole as an asset, in the same way that a company might evaluate any other asset that it owns or controls. Questions might, thus, concern liquidation worth, maintenance cost, adding value and so on. Equally, corporately the interest might lie in the rôle that the information system plays in the financial, functional or operational health of the company. This perspective can be seen also in the Currall \& McKinney, (2006) model of the value to an organisation of its information (see Figure 4).

\section{[Figure 4 near here]}

The sorts of questions and framework that guide judgement making will be those identified in Column 4 of Table 1. Fundamentally, corporate information evaluation is concerned with answering the question:

'How critical is this information to the core operation of the business and what sort of financial asset does it represent?'

Corporate information is qualified as such by being involved in the corporate information evaluation process. It is defined here as follows:

Corporate information is the totality of information embodied in an information system and which represents a commodity or resource asset to the company.

The sorts of information that is of interest at a corporate level is that embodied in such systems as knowledge bases such as databases and expert systems and in process support tools such as CAD systems, document management systems, function information repositories (served through portals and gateways) and so on.

It should be emphasized that - in the current absence of automatic means of information evaluation - each instance of evaluation, irrespective of the 'perspective' from which it 
is carried out must be done by an individual (or perhaps individuals working together). This should not be taken to mean, however, that all evaluations can thus be construed as 'personal' in the sense meant here.

\subsection{The Motivational Dimension}

Part of the context of an information evaluation event (IEE) is the reason or motivation for its taking place. In order to provide a better understanding of the nature and diversity of the evaluation process within an engineering enterprise, the authors have developed a taxonomy of motivations (see Figure 5). The elements in this taxonomy include both high-level motivations for evaluation and also post-evaluative actions. These postevaluation actions can be interpreted also as motivations, that is to say, the premeditated intent that motivates the activity of information evaluation. For example, a task associated with decision-making about information storage might be motivated by a desire to reduce storage overheads, i.e. a high-level motivation of 'reduction'. The underlying motivation would be a desire for information 'disposal' - identified here as a post-evaluation action - perhaps in order to minimize storage costs by means of eradicating duplication or to aid organization merely by a reduction in organizable entities.

\section{[Figure 5 near here]}

Each post-evaluative action in this taxonomy will be associated commonly with one or more of the three organizational perspectives introduced in Section 3.1. It is clear that the set of post-evaluative actions appropriate to each organizational context will intersect incompletely. For example, the 'push' action (that is the purposeful delivery of information based on the anticipated need of the recipient) is common to both personallevel and enterprise-level evaluation activity but outside the ambit of the corporate-level context. Likewise the concept of information 'use' is appropriate only to the personal level. Identifying common post-evaluation actions is a necessary precursor to clarification of the details of the information evaluation process in terms of the organizational context and understanding the commonalities and differences between IEEs for different contexts. This is particularly necessary if automatic or semi-automatic evaluation tools are to be context sensitive and thus have the potential to be responsive to the needs of the user. This can be seen in respect of the relationship between the information life cycle, the post-evaluation actions and the attributes of information as discussed in the next sub-section.

\subsection{The Information Life Cycle Dimension}

The idea of the information life cycle is well established (e.g. Tallon \& Scannell, 2007; Treasury Board of Canada, 2004; Borgman, 1996) although there is perhaps more logic in saying life line, since the life of information is not cyclical nor the stages it passes through strictly ordered. Notwithstanding this, by identifying how evaluation motivation and post-evaluation actions map onto the life of information it can be seen how the information evaluation process differs at different stages. By way of example, the postevaluation actions have been mapped onto the life cycle developed for the Framework for the Management of Information in the Government of Canada (Treasury Board of Canada, 2004). The life-cycle model is generally applicable to enterprise, being 'the steps that information passes through in the course of conducting business activities' (their definition). 
It can been seen in Table 2, below, how different post-evaluation actions are appropriate at different stages of information life, which themselves are associated with different motivations for activities associated with information management. For example, it can be seen that the activity of organization is related to such post-evaluation actions as, say, indexing or the addition of descriptive metadata, which would place the information in some pre-devised classification. This treatment provides an indication of the points in the life cycle where support for information evaluation might be most effective.

\begin{tabular}{|l|l|l|}
\hline $\begin{array}{l}\text { Life Cycle Stages } \\
\text { (Treasury Board of Canada } \\
\text { model) }\end{array}$ & $\begin{array}{l}\text { Motivation/Post- } \\
\text { evaluation Action }\end{array}$ & $\begin{array}{l}\text { Quality Attributes } \\
\text { (from Gonçalves, et al., } \\
\text { 2007) }\end{array}$ \\
\hline Planning & - & - \\
\hline $\begin{array}{l}\text { Collection, Creation, } \\
\text { Receipt \& Capture }\end{array}$ & $\begin{array}{l}\text { Create (from existing), } \\
\text { capture, acquire, } \\
\text { accept/contract/subscribe }\end{array}$ & $\begin{array}{l}\text { Similarity, preservability, } \\
\text { timeliness }\end{array}$ \\
\hline Organization & $\begin{array}{l}\text { Index, log/register, link to, } \\
\text { augment, classify }\end{array}$ & $\begin{array}{l}\text { Accuracy, completeness, } \\
\text { conformance }\end{array}$ \\
\hline Use \& Dissemination & $\begin{array}{l}\text { Use, publish, place, push, } \\
\text { syndicate }\end{array}$ & $\begin{array}{l}\text { Pertinence, significance, } \\
\text { accessibility, timeliness, } \\
\text { relevance }\end{array}$ \\
\hline $\begin{array}{l}\text { Maintenance, Protection } \\
\text { \& Preservation }\end{array}$ & $\begin{array}{l}\text { Augment, aggregate, } \\
\text { integrate, revise, preserve, } \\
\text { archive, pool }\end{array}$ & $\begin{array}{l}\text { Accessibility, } \\
\text { preservability, similarity, } \\
\text { timeliness }\end{array}$ \\
\hline Disposition & Dispose of, sell & - \\
\hline Evaluation & Reject & - \\
\hline
\end{tabular}

Table 2. Post-evaluation actions and information quality attributes mapped on to the information life cycle (as it is conceived by the Treasury Board of Canada, 2004)

When assessing the value of information it is necessary to consider the extent to which an information entity exhibits certain characteristics (for example, quality) which itself may be governed by the value of one or more attributes (e.g. accuracy, clarity, etc). These information attributes and characteristics have been considered elsewhere by the authors (e.g. Zhao et al., 2007). It is possible, then, to suggest which attributes of information may be of greatest interest at particular stages of the life cycle and associated with concomitant motivations or post-evaluation actions. This has been demonstrated in principle by, for example Gonçalves et al., (2007) in consideration of quality metrics for the digital library (an example of an 'information system'). The Gonçalves attributes are shown in column 3 of Table 2 by way of illustration mapped against the information life cycle stages.

An evaluation environment can be imagined which would assist the user in making judgements about the value of a piece of information using appropriate variables and appropriate metrics which were sensitive to the context of the evaluation event in hand. Equally, an automatic system can be envisaged where attributes appropriate to the information's current stage of life cycle may be invoked for the purposes of evaluation. 


\section{Automatic AND Semi-Automatic Information eVAluation}

The analysis given in this paper suggests that the details of the process of information evaluation and the things involved in that process will differ quite markedly according to the precise context in which that evaluation is taking place. As argued here, the context embraces a number of key things including the role of the evaluator and the organizational level at which evaluation is taking place, the sort information entity that is being evaluated, and so on.

These considerations are important if method is to be brought to the process of evaluation, especially so if either automatic or semi-automatic evaluation is to be accomplished. Automatic evaluation implies that the task of making value judgements will be carried out entirely by computer; semi-automatic evaluation that human judgement will be augmented by computer assistance. Computational support of any degree, however, requires the prior identification of the entities being manipulated and an associated understanding of the processes being modelled. Unless this is done then the necessary context-sensitivity required of a successful computational tool will not be achieved.

The authors have undertaken the analysis of the decision-making process and information characteristics of interest in respect of legacy information in an engineering enterprise. This has provided the starting-point for a fully automatic method of evaluating such information for the purposes of use or disposal (see Zhao et al., 2008b). The approach shows the potential for such an approach that could deal with the large volumes of information being generated.

The tool, possibly the method of implementation too, would have been quite different had, for example, automatic evaluation of information as a corporate asset been the task. For the purposes of exemplifying a semi-automated system, an information evaluation user interface might be envisaged which has a context-sensitive menu system allowing the presentation to the user of appropriate choices for selection of such things as evaluation criteria and value metrics. The structure of the interface would help the user through the process allowing, say, the user to rank information characteristics according to perceived importance, to weight contributory attribute values accordingly, and to add local knowledge important to the evaluation process.

Thus the dimensions of information evaluation treated in this paper together with other, more detailed, aspects treated in the authors' associated work (see references in the Introduction) provide a foundation for modelling the information evaluation process for the purposes of computer-supported information evaluation.

\section{CONCLUSION}

The paper identifies and defines a number of important variables associated with information evaluation. These include the objects of evaluation, the high-level operational contexts in which evaluation takes place, the motivations and postevaluation actions associated with these contexts and how they and information entity attributes can be mapped on to the information life cycle. The natural variability in the overall circumstance of an evaluation event derived from these variables suggests that any attempt at providing universally applicable methodologies or mechanisms for information evaluation, indeed any support for information evaluation that does not take into account the context, will be of little value. That is not to say that methods for 
support cannot be attempted, but that they and the derived mechanism must be flexible and responsive to the influences that characterize the specific information evaluation event. These key influences are:

The information entity being assessed, that is, information fragment, object or system.

- The organizational level at which the evaluation is taking place.

- The motivation for the evaluation and the stage in the information life in which it occurs.

- The critical attribute set; that is, those characteristics or qualities of the information that are of interest in the evaluation, and how these should be measured.

In order to provide an automatic or semi-automatic environment for information evaluation support, prior decisions must be taken about which variable values will be encountered and thus must be taken into account in such a system.

The topics and considerations introduced here have provided the foundational framework for the information that must be provided to an automatic or semi-automatic system for information evaluation. Similar analyses by the authors relating to information evaluation characteristics, attributes and metrics will be found elsewhere including in works cited earlier.

\section{ACKNOWLEDGEMENTS}

The research work presented here was undertaken under the aegis of the Knowledge and Information Management (KIM) Through-Life Grand Challenge Project (www.kimproject.org) funded primarily by the Engineering and Physical Research Council (EPSRC) Grant No. EP/C534220/1 and the University of Bath's Innovative Design and Manufacturing Research Centre (IdMRC) Grant No. EP/E00184X/1.

\section{REFERENCES}

Borgman, C.L. (1996). Social Aspects of Digital Libraries. 1st ACM International Conference on Digital Libraries (Fox, E.A., \& Marchionini, G., Eds.), pp. 170-171. ACM, Bethesda, MD.

Buckland, M.K. (1991). Information as Thing. Journal of the American Society for Information Science 42(5), 351-360.

CCSDS. (2002). CCSDS 650.0-B-1: Reference Model for an Open Archival Information System (OAIS). Blue Book. Issue 1. January 2002. Adopted as ISO 14721:2003. In. Consultative Committee for Space Data Systems.

Cohen, F., S. (1950). Field Theory and Judicial Logic. Yale Law Journal 59, 238-272.

Currall, J., \& McKinney, P. (2006). Investing in Value: a perspective on digital preservation. D-Lib Magazine 12(4).

Curtis Wright, H. (1976). The Immateriality of Information. Journal of Library History 11(4), 297.

Darlington, M.J., Culley, S.J., \& Zhao, S. (2008). Information Characteristics \& Attributes: conceptualization and definition as the basis for measurement of information value. Internal Report No. 01/08, Department of Mechanical Engineering, University of Bath. 
Edmunds, A., \& Morris, A. (2000). The Problem of Information Overload in Business Organisations: a review of the literature. International Journal of Information Management 20, 17-28.

Eppler, M.J., \& Mengis, J. (2004). The Concept of Information Overload: a review of literature from organization science, accounting, marketing, MIS and related disciplines. The Information Society, :, 20(5), 325-344.

Glushko, R.J., \& McGrath, T., Eds. (2005). Document Engineering: analysing and designing document for business information and web services. MIT Press, Mass.

Gonçalves, M.A., Moreira, B.L., Fox, E.A., \& Watson, L.T. (2007). What is a good digital library? - defining a quality model for digital libraries. Information Processing Management 43(5), 1416-1437.

Inc. Staff. (2003). Data Data. In INC Magazine, http://www.inc.com/magazine/19990101/715.html.

KIM. (2007). KIM Project Conference 2007, Knowledge \& Information Management Through Life. KIM Project Conference 2007, (Darlington, M., Ed.). KIM Project, Loughborough.

Macdonald, A., \& Lord, P. (2002). Digital Data Curation Task Force: report of the task force strategy discussion day. In. JISC, Downloaded 260508:

http://www.jisc.ac.uk/publications.aspx.

Machlup, F., \& Mansfield, U. (1980). The Study of Information: interdisciplinary messages. John Wiley, New York.

Meadows, C., T. , \& Yuan, W. (1997). Measuring the Impact of Information: defining the concepts. Information Processing \& Management 33(6), 697-714.

Tallon, P.P., \& Scannell, R. (2007). Information Life Cycle Management

Communication of the ACM Archive 50(11), 65-69.

Tang, L.C.M., Zhao, Y., Austin, S.A., Darlington, M.J., \& Culley, S.J. (2007). Knowledge and Information Evaluation Practice - an exploratory study in a construction firm. In CIB W102 3rd International Conference. Stuttgart.

Treasury Board of Canada. (2004). Framework for the Management of Information (FMI) in the Government of Canada. In. Government of Canada.

Waddington, P. (1996). Dying for Information: An Investigation of Information Overload in the UK and Worldwide. In. Reuters Business Information,, London.

Zhao, S. (2007). A Review of Cross-Sector Approaches to Information Evaluation. In Internal Report, No. 07/07. Department of Mechanical Engineering, University of Bath.

Zhao, S., Tang, L., Darlington, M., Austin, S., \& Culley, S. (2008a). Information Evaluation: empirical investigations in engineering organizations. In ECIME, 2nd European Conference on Information Management and Evaluation. Royal Holloway, University of London, UK.

Zhao, Y., Tang, L.C.M., Darlington, M.J., Austin, S.A., \& Culley, S.J. (2007). Establishing Valuing Characteristics for Engineering Design Information. In 16th International Conference on Engineering Design, ICED 07. Cité des Sciences et de l'Industrie, Paris.

Zhao, Y., Tang, L.C.M., Darlington, M.J., Austin, S.A., \& Culley, S.J. (2008b). High Value Information in Engineering Organisations. International Journal of Information Management 28(3).

Ziade, R., \& Kittredge, M. (2005). Information objects: applying cognitive load theory \& object-oriented thinking to information design, Arc90 whitepaper. In. Arc90. 


\begin{tabular}{|c|c|c|c|}
\hline & PERSONAL & ENTERPRISE & CORPORATE \\
\hline $\begin{array}{l}\text { Information } \\
\text { Evaluation } \\
\text { Process }\end{array}$ & $\begin{array}{l}\text { Carried out on an } \\
\text { information entity in } \\
\text { respect of a current } \\
\text { or predictable } \\
\text { information need }\end{array}$ & $\begin{array}{l}\text { Carried out on an } \\
\text { information entity which } \\
\text { predicts its future } \\
\text { capacity to satisfy an } \\
\text { employee's information } \\
\text { need. }\end{array}$ & $\begin{array}{l}\text { Carried out on an } \\
\text { information entity } \\
\text { (viewed as an asset) } \\
\text { which assigns to it a } \\
\text { monetary value or a } \\
\text { score according to the } \\
\text { extent to which it is } \\
\text { necessary for the } \\
\text { company to act } \\
\text { profitably. }\end{array}$ \\
\hline $\begin{array}{l}\text { Impact } \\
\text { Horizon }\end{array}$ & Now, near future & Tactical, shorter term & Strategic, longer term \\
\hline Role & As an individual & $\begin{array}{l}\text { Knowledge manager or } \\
\text { team/project manager }\end{array}$ & Senior manager \\
\hline $\begin{array}{l}\text { Key } \\
\text { Question }\end{array}$ & $\begin{array}{l}\text { Does this } \\
\text { information help me } \\
\text { to make a better } \\
\text { decision for the task } \\
\text { that I am doing? }\end{array}$ & $\begin{array}{l}\text { Is the information of } \\
\text { sufficient use to be } \\
\text { made available to team, } \\
\text { group, individual in } \\
\text { anticipation of likely } \\
\text { tasks? }\end{array}$ & $\begin{array}{l}\text { How critical is this } \\
\text { information to the } \\
\text { operation of the } \\
\text { business and what } \\
\text { sort of financial asset } \\
\text { does it represent? }\end{array}$ \\
\hline $\begin{array}{l}\text { Appropriate } \\
\text { Decision }\end{array}$ & $\begin{array}{l}\text { Use, store, discard, } \\
\text { reject, improve, } \\
\text { push }\end{array}$ & $\begin{array}{l}\text { Store, accept, discard, } \\
\text { reject, push }\end{array}$ & $\begin{array}{l}\text { Acquire, store (various } \\
\text { types), maintain, } \\
\text { curate, discard }\end{array}$ \\
\hline Value & $\begin{array}{l}\text { Capacity to fulfil an } \\
\text { information need, } \\
\text { solve a problem, or } \\
\text { support a decision }\end{array}$ & $\begin{array}{l}\text { Capacity to support a } \\
\text { process or activity } \\
\text { within the company }\end{array}$ & $\begin{array}{l}\text { Capacity to maintain, } \\
\text { support or increase } \\
\text { company asset value }\end{array}$ \\
\hline $\begin{array}{l}\text { Information } \\
\text { Entity Type }\end{array}$ & $\begin{array}{l}\text { Information } \\
\text { Objects } \\
\text { Information } \\
\text { Fragments } \\
\text { - Extracts from } \\
\text { documents } \\
\text { - Facts and figures }\end{array}$ & $\begin{array}{l}\text { Information Objects: } \\
\text { - Database content } \\
\text { - Information services } \\
\text { content } \\
\text { - Subscription matter } \\
\text { - Standards/regulations } \\
\text { - Best practices guides } \\
\text { - Manuals, etc. }\end{array}$ & $\begin{array}{l}\text { Information } \\
\text { Systems: } \\
\text { - Knowledge bases } \\
\text { (e.g. database, expert } \\
\text { system) } \\
\text { - Tools (CAD, EDMS, } \\
\text { etc) } \\
\text { - Libraries } \\
\text { - Document collections }\end{array}$ \\
\hline
\end{tabular}

Table 1. The three perspectives of the organizational dimension 


\begin{tabular}{l|ll} 
& \multicolumn{1}{|c}{ INTANGIBLE } & \multicolumn{1}{c}{ TANGIBLE } \\
\hline \multirow{2}{*}{ ENTITY } & $\begin{array}{l}\text { Information-as-knowledge } \\
\text { Knowledge }\end{array}$ & $\begin{array}{l}\text { INFORMATION-AS-THING } \\
\text { Data, document }\end{array}$ \\
\hline \multirow{2}{*}{ PROCESS } & $\begin{array}{ll}\text { Information-as-process } \\
\text { Becoming informed }\end{array}$ & $\begin{array}{l}\text { Information processing } \\
\text { Data processing }\end{array}$
\end{tabular}

Figure 1. Buckland's (1991) categorization of information as intangible and tangible, identifying 'information-as-thing' 


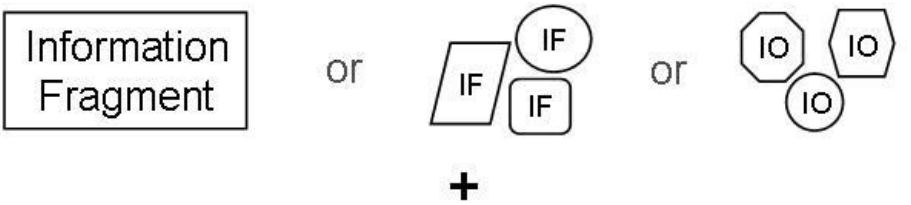

Context-bearing information

e.g. title, provenance information, date information, affiliations and physical form

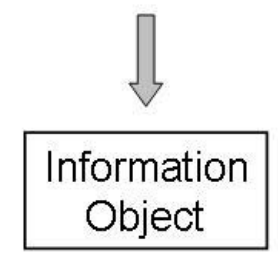

Figure 2. The relation between the Information Fragment and the Information Object 


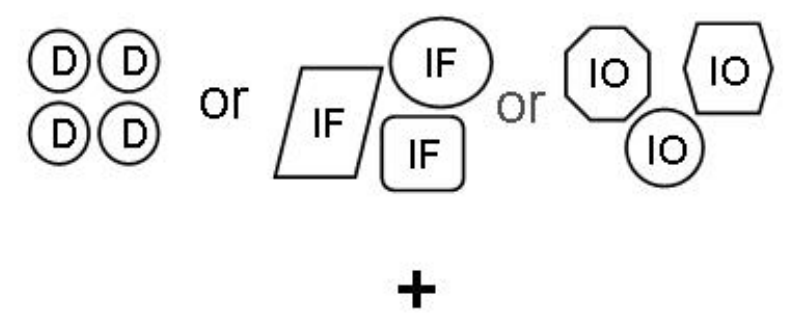

Organizational Infrastructure

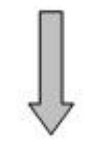

Information System

Figure 3. The relationship between the Information Object and the Information System 


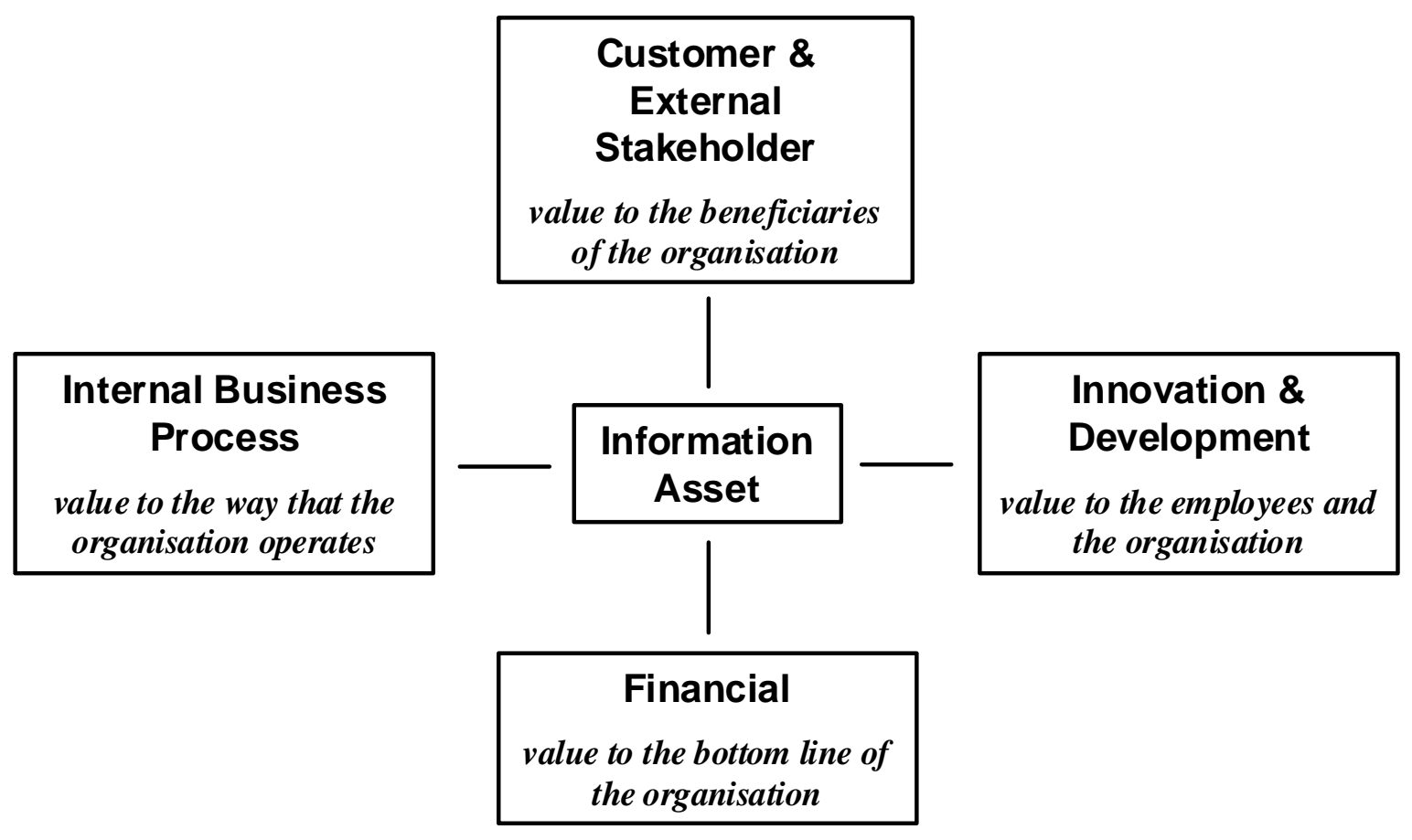

Figure 4. Information-as-asset as interpreted by Curral \& McKinney, 2006 


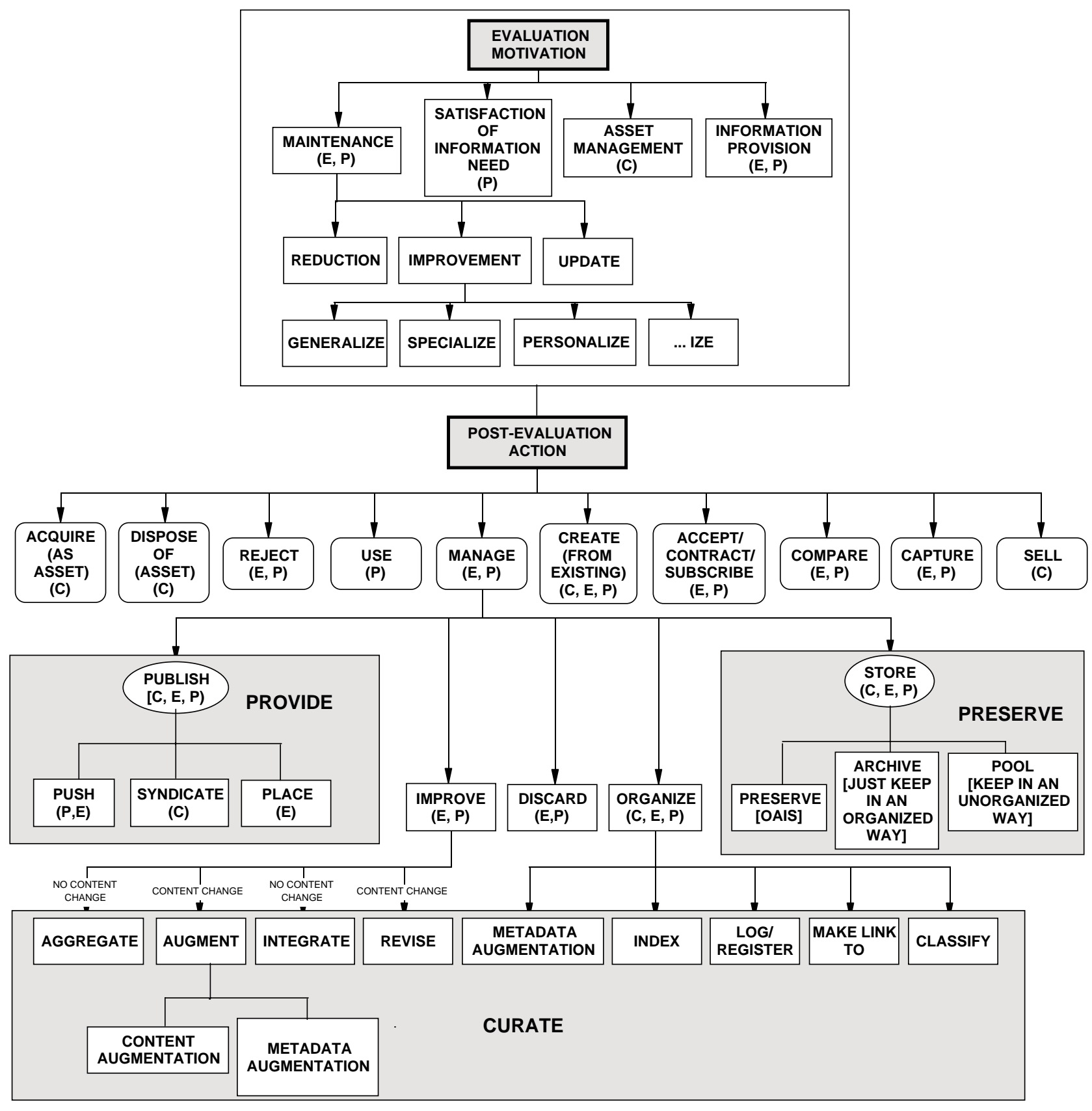

Figure 5. A taxonomy of high-level motivations and post-evaluative actions with associations with the three perspectives of evaluation shown as bracketed initials (C, E, P) 